\title{
The Gender Factor Effect on Saudi Learners' Perceptions of Using Social Media on Their Social Interaction
}

\author{
Boushra Abdul-Aziz AlGhamdi ${ }^{1}$, Shorouq Ali AL-Garni ${ }^{1}$ \& Maysa M. Qutob ${ }^{1}$ \\ ${ }^{1}$ English Language Institute, King Abdulaziz University, Jeddah, Saudi Arabia \\ Correspondence: Maysa M. Qutob, English Language Institute, King Abdulaziz University, Jeddah Saudi Arabia. \\ E-mail: mqutob0001@stu.kau.edu.sa
}

\author{
Received: August 5, 2018 Accepted: September 11, 2018 Online Published: September 13, 2018 \\ doi: 10.5539/elt.v11n10p30 URL: http://doi.org/10.5539/elt.v11n10p30
}

\begin{abstract}
This study compares males and females perception of the effect of social media on their social interaction to understand the difference between both genders. The study follows a mixed-method methodology using a questionnaire with closed-ended items and open-ended questions. Responses to the questionnaire are collected form 207 male and female students from a public university in Saudi Arabia. In general, the results of the questionnaire are insignificant which indicate that there are no differences between both genders. However, the results of the open-ended questions show that females have a negative view of the effect of social media on human relations while males have a positive point of view. However, both genders have a positive point of view regarding balancing between friends and family in real life and virtual world through time management.
\end{abstract}

Keywords: culture, social interaction, social media, interaction, males, females, gender differences

\section{Introduction}

Albert Einstein once said "I fear the day when technology will overlap with our humanity. The world will only have a generation of idiots." In that quote, Einstein represents the debate that always arises around social media and its use, is using it advantageous or disadvantageous? (O'Keeffe \& Clarke-Pearson, 2011). However, with the growth of social media tools such as Facebook, WhatsApp, and YouTube the literature is still lacking especially when it comes to these tools' effect on social interactions. Thus, this research aim is to try and find out what young Saudi learners of King AbdulAziz University think of the effect of social media on their social interaction. To fulfill that aim, the study posed the following questions; what are the perceptions of male and female Saudi students on social media's effect on social interactions, and are there any differences between the perceptions of the two genders?

\subsection{Social Media}

Social Media and its effects has been defined and studied widely and from various angels. Kaplan and Haenlein (2010) defines social media as "a group of Internet-based applications that build on the ideological and technological foundations of Web 2.0, and that allow the creation and exchange of User Generated Content" (p. 61). Therefore, applications that require the use of internet, human interactions and content such Twitter, Facebook and YouTube are included in this definition. Some scholars focus on the advantages and disadvantages of social media such as various communicative opportunities and exposure to bullying respectively (O'Keeffe \& Clarke-Pearson, 2011). Others choose a certain aspect and study the effect of social media on it, like what Paul, Baker, and Cochran (2012) did in their study where the focus was on academic performance. In addition, some studies were done to examine the effect of social media on youth behavior and how it might help in changing views through attracting crowds such as the study done by Njoroge (2011). Other studies sought the effect of gender differences on social media use in light of factors such as identifying with the internet and feeling anxious as in Joiner et al.'s (2005) study. Their study used a quantitative researching method via a questionnaire sent to 608 participants from the first year of undergraduate students majored in psychology, however, the majority of responses were from female participants (490), an issue similar to what the current study faced. One of their findings which pertain to the current study is that females and males use internet for communication similarly, thus, disagreeing with what Barker (2009) found in her study. The study done by Barker (2009) examined the influence of gender difference, self-esteem and group-identity on the usage of social media, which revealed that females scored higher when it comes to using social media for communicational and relational purposes. 


\subsection{Social Media and Social Interactions}

It seems evident from the literature that there are contrasting views on the effect of social media on social interactions. Social interactions is a term used in the study to represent continuous exchanges among people whether online or offline. Therefore, only exchanges with people who are considered acquaintances and relatives are meant here. There is the view that online communication might lead to distancing oneself from his/her family and friends to indulge in various activities with strangers (Kraut et al., 1998; Nie, 2001 cited in Haythornthwaite, 2011). On the other hand, social media could be efficient in connecting people with their remote relatives and friends (LaRose et al. as cited in Haythornthwaite, 2011). Supporting this positive point of view on social media is a work by Quan-Haase, Wellman, Witte, and Hampton (2002) where they discuss a survey taken from National Geography (1998) website about the internet effect on social interactions among other factors. They revealed that "the Internet is increasing social capital, civic engagement, and developing a sense of belonging to online community" (p. 319). A more balanced view stated by Jensen (2015) who argues that social interactions are different and special in the two forms (real or online), and both could present various opportunities. Furthermore, some works have been conducted to study the relation between high social media and internet usage, and loneliness (Moody, 2001).

Related to the current study is a study done by Baym, Zhang, and Lin (2004) where they present two studies examining the social interactions in face-to-face interactions, on the telephone and over social media. However, unlike the current study which focuses on the gender differences between university students' perceptions of social media effect on their social interaction, Baym's et al. (2004) study focuses on social interactions' quality and quantity in different mediums. Their sample consisted of 52 students from two American universities. The authors used two methods to collect their data. The first one was a diary to report the amount of exchanges in the three mediums, while the other method was a survey conducted to see the different goals of these interactions, their setting and their quality. The main findings of the study show that real life interactions among the targeted sample scored the highest over social media and phone interactions when users are of the same or near the living area. In addition, the authors add that "instead of a trade-off between high quality face-to-face conversations and lower quality internet interactions, students are supplementing high quality face-to-face conversations and telephone calls with really good internet interactions" (316).

By looking through the literature, it seems that the topic of different gender views towards social media effects on social interactions is very rare, and in the context of Saudi Arabia it is rather non-existent to the researchers knowledge. Furthermore, the bulk of these studies are seemingly outdated since the most used form of online interaction is the email, which is nowadays considered mostly a tool for formal requests and applications. Therefore, this study aims to fill that gap by providing what does the young Saudi users of social media (WhatsApp, Twitter, etc.) think of its effect on their social interactions.

\section{Methodology}

This research uses a mixed-method, to compare male and female King Abdul-Aziz University students' opinions of the effect of social media on their social interaction, in the academic year 2017-2018, in order to gain a better understanding of gender differences towards social media.

\subsection{Participants}

University students are a suitable sample to participate in a study to understand the effect of social media on their social interaction as they are likely to integrate social media in their daily lives (Pew Project on the Internet and American Life, 2002, as cited in Baym et al., 2004). Participants are from a large public university in Jeddah, Saudi Arabia, with 62 (29.5\%) males and 146 (70.5\%) females, among the 207 participants, $76 \%$ in science courses and $24 \%$ in the arts. The majority of the participants' ages range between $18-25$, most of whom spend 4-6 hours daily on social media with WhatsApp being the most popular social media application.

\subsection{Instruments}

A questionnaire has been prepared in the Arabic language to collect data about the effect of social media on social interaction, which includes demographics of the participants, fifteen close-ended items, and two open-ended questions. In addition, a pilot study was performed on males and females from the same public university and administered by SPSS to ensure reliability and validity of the questionnaire. Moreover, an expert from the field provided feedback on the items on the questionnaire, which helped the authors to improve the wording and structure of the items. After taking ethical approval from the Graduate Study and Academic Research Unit, participants received the questionnaire URL through email invitations, WhatsApp broadcast, and Twitter, where after they chose their preference from a three point Likert scale; agree, neutral, and disagree. Finally, both the 
quantitative and qualitative data were separated into two excel sheets, then the qualitative answers were transferred into numbers in a range from agree $=3$ down to disagree $=1$.

\subsection{Data Analysis Procedure}

\subsubsection{Analysis of Quantitative Data}

Participants completed the closed-items in the questionnaire to provide quantitative data, which was then analyzed using SPSS 21.0 to extract Cronbach's alpha to ensure reliability. Validity was ensured by calculating internal consistency and examining the correlation between each individual item and the total score of the questionnaire. Moreover, SPSS was used to create descriptive statistics, which gives an overall estimation of the data, including means, standard deviation and frequency, for both males and females separately. Additionally, inferential statistics, using the Mann-Whitney U test, was implemented to examine the difference between males and females.

\subsubsection{Analysis of Qualitative Data}

In addition, the qualitative data is collected by conducting semi-structured interviews consisting of two open-ended questions. The first question was "Do you think social media affect relationships positively or negatively? Why?" and the second question was "How can you balance between friends and family in real life and virtual life?". The questions were sent to the participants via Google form then the answers were translated into English and thematically analyzed. Furthermore, each piece of information was given a code and then categorized using NVivo, a qualitative analysis software. Moreover, the answers were interpreted to present the differences between both genders' point of view.

\section{Results}

\subsection{Reliability and Validity of the Questionnaire}

Each item was given a score ranging between (1-3), where $1=$ disagree, $2=$ neutral $\& 3=$ agree. As there were 15 items in the scale, the maximum score was 45 . After administration of the data from the main sample of the population, reliability was re-examined. Cronbach's Alpha is .8; this value is significant and indicates a high reliability of the scale. As for the validity, internal consistency was investigated, and all items show significant correlation with the total score. Table 1 shows the correlations between each item and the total score of the scale.

Table 1. Correlations between items and the total score of the scale

\begin{tabular}{lll}
\hline Item & Correlation & Significance \\
\hline 1 & 0.48 & 0.001 \\
2 & 0.61 & 0.001 \\
3 & 0.52 & 0.001 \\
4 & 0.49 & 0.001 \\
5 & 0.31 & 0.001 \\
6 & 0.36 & 0.001 \\
7 & 0.58 & 0.001 \\
8 & 0.54 & 0.001 \\
9 & 0.63 & 0.001 \\
10 & 0.64 & 0.001 \\
11 & 0.6 & 0.001 \\
12 & 0.3 & 0.001 \\
13 & 0.67 & 0.001 \\
14 & 0.59 & 0.001 \\
15 & 0.39 & 0.001 \\
\hline
\end{tabular}


Table 2. Means and standard deviations for each group

\begin{tabular}{lll}
\hline Item & Mean & Standard deviation \\
\hline Males & 30.38 & 7.13 \\
Females & 30.58 & 5.93 \\
\hline
\end{tabular}

\subsection{Descriptive Statistics}

Means and standard deviations for the total scores of participants were calculated for both male and female students (see Table 2). Additionally, the percentages of positive neutral and negative responses to each item were analyzed (see table 3 for percentiles). Differences in percentages are obvious in some items, for example, in item 1, females find it easier to communicate with strangers, as $47.3 \%$ of females agree with the statement, as opposed to $27.8 \%$ of males. In item $4,66.7 \%$ of males, in contrast to $29.7 \%$ of females, express their interest in communicating with others through social media.

However, both males and females show roughly similar responses to the remainder of the items. A high percentage of participants agree with item 5, which states that they do not recognize social media as a barrier to communicating with others in reality. Additionally, $46.3 \%$ of males and $48.3 \%$ of females indicate that they spend a long time communicating with others on social media (item 9). In addition, $51.9 \%$ of males and $52.7 \%$ of females agree on the ability to express their feelings to others through social media (item 11 ). Moreover, $75.9 \%$ of males and $86 \%$ of females agree on the importance of social media on acculturation (item12).

Table 3. Percentages of positive, neutral and negative responses to each item

\begin{tabular}{lllllll}
\hline Item & Positive & $\begin{array}{l}\text { Male } \\
\text { Neutral }\end{array}$ & Negative & Positive & $\begin{array}{l}\text { Female } \\
\text { Neutral }\end{array}$ & Negative \\
\hline 1 & 27.8 & 27.8 & 44.4 & 47.3 & 32 & 20.7 \\
2 & 22.2 & 31.5 & 46.3 & 18.7 & 34 & 47.3 \\
3 & 18.5 & 31.5 & 50 & 22.7 & 22.7 & 54.7 \\
4 & 66.7 & 24.1 & 9.3 & 49.7 & 34.3 & 16 \\
5 & 59.3 & 13 & 27.8 & 60 & 20.7 & 19.3 \\
6 & 27.8 & 35.3 & 37 & 18.7 & 29.3 & 52 \\
7 & 40.7 & 14.8 & 44.4 & 41.3 & 25.3 & 33.3 \\
8 & 33.3 & 25.7 & 40.9 & 28.7 & 28.7 & 42.7 \\
9 & 46.3 & 16.7 & 37 & 48.7 & 22 & 29.3 \\
10 & 38.9 & 14.8 & 46.3 & 41.3 & 31.3 & 27.3 \\
11 & 51.9 & 16.7 & 31.5 & 52.7 & 21.3 & 26 \\
12 & 75.9 & 11.1 & 13 & 86 & 10 & 4 \\
13 & 22.2 & 25.9 & 51.9 & 18.7 & 17.3 & 64 \\
14 & 16.7 & 14.8 & 68.5 & 15.3 & 16 & 68.7 \\
15 & 44.4 & 16.7 & 38.9 & 50.7 & 14.3 & 34 \\
\hline
\end{tabular}

On the other hand, both genders disagree with the statement, "friends on social media are more approachable than friends in reality" (item13), 51.9\% males and $64 \%$ females, an equal number of males and females $68.7 \%$ do not agree with the statement that they prefer to discuss problems with friends on social media rather than friends in reality (item 14).

Differences between males and females points of view. The differences between males and females points of view on the impact of social media on their social interaction were tested. The assumption of equality of variances in the two independent groups was violated, and Levine's test $F$ values was significant, $F=4.48, p<.05$. Therefore, the non-parametric Mann-Whitney U test was used to compare the mean ranks of the two groups. The mean rank of 
the scores for female students is 103.03 , whereas the mean rank of the scores for male students is 101.03 , and the difference between the two ranks is not significant, $\mathrm{Z}=.21, p=\mathrm{ns}$.

\subsection{Qualitative Data Results}

Table 4. The differences between males' and females' views of the effect of social media on relationships

\begin{tabular}{|c|c|c|c|c|}
\hline Sample & Theme & Description & Description & Sources \\
\hline Females & $\begin{array}{l}\text { Negative view of the effect } \\
\text { of social media on human } \\
\text { relations }\end{array}$ & $\begin{array}{l}\text { It has a disadvantageous effect } \\
\text { on people's relationships } \\
\text { because people do not express } \\
\text { their emotions vividly on the } \\
\text { internet. The overuse of social } \\
\text { media has a bad effect on } \\
\text { people's relations with each } \\
\text { other. }\end{array}$ & 59 & $\begin{array}{l}\text { An open-ended } \\
\text { question }\end{array}$ \\
\hline Males & $\begin{array}{l}\text { Positive view of the effect } \\
\text { of social media on human } \\
\text { relations }\end{array}$ & $\begin{array}{l}\text { It has an advantageous impact } \\
\text { on people's relationships } \\
\text { becaus it makes the } \\
\text { relationship between family } \\
\text { members closer and stronger } \\
\text { since they can contact each } \\
\text { other at anytime and anywhere. } \\
\text { It is effective for everyday use } \\
\text { if the user knew how to use } \\
\text { social media for } \\
\text { communicating and discussing } \\
\text { important topics with others. }\end{array}$ & 22 & $\begin{array}{l}\text { An open-ended } \\
\text { question }\end{array}$ \\
\hline
\end{tabular}

Regarding the first open-ended question which is "Do you think social media affect relationships positively or negatively? Why?" Gender difference plays a very crucial role in this question. The data gathered from the female section indicates that they have an overall negative view of using social media for creating online relationships. Most of the answers were with the idea that real contact with relatives and friends can be very beneficial and replaces the use of social media. Based on the previous statement, one of the disadvantageous effects of social media is that it makes people prefer using it for interaction instead of meeting in real life settings. Another negative view as stated by one of the female students, "it has a negative effect if the user kept using their cell-phones even in the presence of their family members." Moreover, using social media can diminish relationships since people tend to use written text instead of spoken discussion which may lead to misunderstandings and vague delivery of ideas. As an overall statement, social media became a very dangerous platform for people's use since anyone can post anything without bearing in mind people's feelings and viewpoints.

The male section had a different point of view of the impact of social media on human relations. They had a very optimistic point of view which is reflected in most of the participants' answers. One of the participants answered that "social media can make the relationship between family members and friends closer than in real life." The previous answer indicates that males prefer spending most of their time online than in real life events which can be seen in many Saudi families. Another positive point of view is that social media facilitates the interaction with friends who live abroad and can be contacted anytime and anywhere. Another participant answered, "using social media is effective for planning family gatherings and sharing information about each other." An overall statement, males consider using social media as an effective platform for creating friendships and keeping contact with others than in real life which can be true to some extent. 
Table 5. The relationship between males' and females' views of balancing between friends and family in real life and virtual world

\begin{tabular}{|c|c|c|c|c|}
\hline Sample & Theme & Description & References & Sources \\
\hline Females & $\begin{array}{l}\text { Positive view of } \\
\text { balancing between } \\
\text { friends and family in } \\
\text { real life and virtual } \\
\text { world }\end{array}$ & $\begin{array}{l}\text { Managing time can be very } \\
\text { beneficial in determining the } \\
\text { amount of time spent for } \\
\text { meeting friends and family } \\
\text { members in real life and social } \\
\text { media }\end{array}$ & 58 & $\begin{array}{l}\text { An open-ended } \\
\text { question }\end{array}$ \\
\hline Males & $\begin{array}{l}\text { Positive view of } \\
\text { balancing between } \\
\text { friends and family in } \\
\text { real life and virtual } \\
\text { world }\end{array}$ & $\begin{array}{l}\text { Making a timetable for using } \\
\text { each of the worlds is very helpful } \\
\text { for reaching moderation and } \\
\text { equivalence }\end{array}$ & 13 & $\begin{array}{l}\text { An open-ended } \\
\text { question }\end{array}$ \\
\hline
\end{tabular}

Regarding the second open-ended question which is "How can you balance between friends and family in real life and virtual world?" Both genders were having a positive view of being able to manage time between meeting and contacting friends and family members in real life settings and social media. Both genders were with the idea of spending more time communicating face to face, then using text or voice-chat to interact with others. Some participants of both genders were preferring spending time with family members in real life while communicating with friends on social media. However, most of the answers were indicating that time management and moderation are the best solutions for creating this type of balance.

\section{Discussion}

Gender difference plays a primal role in this research paper to determine the effect of social media on young Saudi learners' social interaction. Male and female students differ in some aspects, while have similar results in others which reflect both genders' viewpoints regarding perceiving social media as a facilitator or barrier for their social interaction. Both genders think that social media does not isolate them from the surrounding society, they spend a long time using social media for communication and tend to express their feelings vividly on it. The previous statement assures that social media plays a very important role in keeping contact with others. As seen in the Saudi context, males and females spend most of their time on the internet and specifically on social media. Both genders find the virtual world as an outlet for them to talk about life matters and meet new people which might not be the case in real life settings. Moreover, both genders disagree with the idea that friends can be approached easily on social media rather than real life and they prefer talking about their problems with friends in real life rather than social media. The previous result indicates that although learners use social media for keeping contact with friends, there are some boundaries for using it, such as not talking about personal issues. Regarding the Saudi context, both genders use the internet for interaction and keeping contact with others, however, they still believe that genuine communications with true friends in real life is safer for them than on the internet. Both genders believe that they can balance between friends and family in real life and virtual world through time management. Some Saudi learners learned that through time management, they can keep a balance between communicating with their family members in real life settings while interacting with their friends on social media. On the other hand, they differ in the sense that females believe that talking to strangers on social media is easy while males think the opposite. The previous sentence indicates that there are strict social boundaries between genders in the Saudi context. Females find it easier to talk and communicate with others on social media since they can disguise their real identity. Such disguise makes them feel more secure and safe. On the other hand, Saudi males find it harder to communicate with strangers on social media since they have spent most of their time dealing with others in real life settings which makes it a more comfortable environment. Another difference is that males declare their interest in talking with friends and family on social media as opposed to females. Both differences indicate that although both genders use social media for making friendships, their concept of what type of relationship they can have is varied. Saudi males can make friendships with everyone with no boundaries since they do not feel anxious or insecure regarding the type of friendships they can make with strangers. However, Saudi females are more cautious when it comes to making friendships on the internet since they have boundaries to the type of relationship they can have on online platforms. On the other hand, females differ from males in thinking that social media has a negative effect on human relations. Females believe that interacting in real life is better than using social media while males disagree since they believe that it makes the relationship with family members and friends closer and stronger. The 
previous sentence describes the situation in the Saudi families. Saudi females appreciate family gatherings in real life and communicating with others face to face. On the other hand, Saudi males prefer talking with everyone on the internet than meeting them in real life.

Regarding associating the findings of the current study to the literature review, this paragraph highlights the major similarities between them. The current study's finding goes in line with O'Keeffe and Clarke-Pearson's (2011) proclamation that social media has advantages and disadvantages regarding having communicative opportunities and bullying. The current study focuses on the importance of keeping contact with friends and family on the internet and having boundaries toward negative use of social media which may lead to bullying and other disadvantageous results. Moreover, Kraut et al. (1998) and Nie (2001) cited in (Haythornthwaite, 2011) argue that online communication may lead to distracting oneself from family members and friends through indulging in online activities with strangers. The previous statement goes in line with the current study's finding in the sense that female members prefer communicating with strangers using social media which may lead to abandoning real-life gatherings. In addition, Hampton et al. (2009) claim that social media can be effective for connecting people with their relatives and friends. The previous statement is similar to the current study in the sense that social media can be efficient in keeping contact with family members and friends who live abroad at anytime and anywhere.

\section{Limitations and Educational Implications}

The current study had 62 males and 146 females as participants which is unbalanced number for a research about gender difference. Both genders were approached equally, however, responses were not received equally because the researchers are all females and that perhaps led to a larger number of relations from the same gender and inefficient distribution among males. Future studies should try and collect an equal amount of data from both genders.

\section{Future Research}

Future research can extensively investigate the effect of social media on young learners' critical thinking, attitudes, and behavior. Also, other researchers could replicate the current study through having a balanced number of participants and on a different contexts. More research projects need to be done on different genders' views towards social media effects on social interactions in the Saudi context.

\section{References}

Barker, V. (2009). Older Adolescents Motivations for Social Network Site Use: The Influence of Gender, Group Identity, and Collective Self-Esteem. CyberPsychology \& Behavior, 12(2), 209-213. https://doi.org/ $10.1089 / \mathrm{cpb} .2008 .0228$

Baym, N. K., Zhang, Y. B., \& Lin, M.-C. (2004). Social interactions across media: Interpersonal communication on the internet, telephone and face-to-face. New Media \& Society, 6(3), 299-318. https://doi.org/10.1177/ 1461444804041438

Haythornthwaite, C. (2005). Social networks and Internet connectivity effects. Information, Community \& Society, 8(2), 125-147. https://doi.org/10.1080/13691180500146185

Jensen, K. B. (2015). What's social about social media? Social Media + Society, 1(1), 205630511557887.

Joiner, R., Gavin, J., Duffield, J., Brosnan, M., Crook, C., Durndell, A., ... Lovatt, P. (2005). Gender, Internet Identification, and Internet Anxiety: Correlates of Internet Use. CyberPsychology \& Behavior, 8(4), 371-378. https://doi.org/10.1089/cpb.2005.8.371

Kaplan, A. M., \& Haenlein, M. (2010). Users of the world, unite! The challenges and opportunities of Social Media. Business horizons, 53(1), 59-68. https://doi.org/10.1016/j.bushor.2009.09.003

Moody, E. J. (2001). Internet use and its relationship to loneliness. CyberPsychology \& Behavior, 4(3), 393-401. https://doi.org/10.1089/109493101300210303

Njoroge, R. (2013). Impacts of social media among the youth on behavior change: a case study of University students in selected universities in Nairobi, Kenya. Unpublished Masters Thesis.

O'Keeffe, G. S., \& Clarke-Pearson, K. (2011). The impact of social media on children, adolescents, and families. Pediatrics, 127(4), 800-804. https://doi.org/10.1542/peds.2011-0054

Quan-Haase, A., Wellman, B., Witte, J. C., \& Hampton, K. N. (2002). Capitalizing on the net: Social contact, civic engagement, and sense of community. The Internet in everyday life, 289-324. https://doi.org /10.1002/9780470774298.ch10 


\section{Copyrights}

Copyright for this article is retained by the author(s), with first publication rights granted to the journal.

This is an open-access article distributed under the terms and conditions of the Creative Commons Attribution license (http://creativecommons.org/licenses/by/4.0/). 